\title{
Isolated, overwhelmed and worried: young first-time mothers asking for information and support online
}

\author{
Ian Ruthven, Steven Buchanan and Cara Jardine \\ Department of Computer and Information Sciences \\ University of Strathclyde \\ United Kingdom
}

ian.ruthven@strath.ac.uk, steven.buchanan@strath.ac.uk, cara.jardine@strath.ac.uk

This is the peer reviewed version of the following article: Ruthven, I. , Buchanan, S. and Jardine, C. (2018), Isolated, overwhelmed, and worried: Young first - time mothers asking for information and support online. Journal of the Association for Information Science and Technology, 69: 1073-1083, which has been published in final form at https://doi.org/10.1002/asi.24037. This article may be used for non-commercial purposes in accordance with Wiley Terms and Conditions for self-archiving. 


\begin{abstract}
This study investigates the emotional content of 174 posts from 162 posters to online forums made by young (age 14-21) first time mothers to understand what emotions are expressed in these posts and how these emotions interact with the types of posts and the indicators of Information Poverty within the posts. Using textual analyses we provide a classification of emotions within posts across three main themes of interaction emotions, response emotions and pre-occupation emotions and show that many requests for information by young first time mothers are motivated by negative emotions. This has implications for how moderators of online news groups respond to online request for help and for understanding how to support vulnerable young parents.
\end{abstract}




\section{Introduction}

In this paper, we look at how young first-time mothers express their information and support needs in online forums, particularly looking at the emotional content of their posts. Motherhood, especially for young mothers, is a significant life change and one that is a highly emotional time. Some emotions are positive, including happiness at becoming a parent, whilst others may be negative: depression from being socially isolated, worry about their new child's development or fear for the future.

Emotions can play an important role in how mothers seek information and social support. Internet forums play a particular role in information support as they can allow people to more freely ask for information, particularly on sensitive topics, and ask for help that is not available in people's immediate social environment (Hasler, Ruthven, \& Buchanan, 2014). Drentea and Moren-Cross (2005) argue that forums allow mothers to get emotional support that is often unavailable in professional settings and O'Mahen et al. (2013) cite forums as having a positive effect on post-natal depression and being an excellent environment for mothers to gain social capital.

This is the first study to focus exclusively on young (aged 14-21) first time mothers and pregnant women to look at how these young women ask for help. As explained below, this group faces particular challenges in transitioning to motherhood, not least the stigma that young motherhood often attracts. Using 174 posts from 162 posters by young first-time mothers as expressed in posts to dedicated Internet discussion groups, this study looks at the emotional content of these needs to look at the emotions that are associated to these requests for information.

As well as providing a new understanding of how emotions are linked to information needs, this study has practical implications in considering how online moderators should response to such requests for information. We first consider the literature related to young motherhood with particular emphasis on the emotional side of young motherhood to explain why this group's online information seeking is of interest.

\section{Literature review}

\section{Motherhood and online information seeking}

Motherhood is a major change in a woman's life (Darvill, Skirton, \& Farrand, 2010) which impacts not only on the practical areas of her life but also on her identity, priority and life goals. Motherhood is a strongly emotional time with many mothers feeling mixed emotions, (Bondas \& Eriksson, 2001). Whilst most parents express happiness at their new role and new family, new mothers can feel 'powerlessness, 3 
insufficiency, guilt, loss, exhaustion, ambivalence, resentment and anger' (Nyström \& Öhrling, 2004). These emotions can arise from physical tiredness, anxiety over their performance as a parent, lack of knowledge over what to expect as a mother, lack of appropriate support and lack of knowledge about what is 'normal' in terms of child development, behaviour and health. A common finding is that mothers are reluctant to discuss the negative aspects of motherhood including depression, for fear of being judged, especially by health professionals (Loudon, Buchanan, \& Ruthven, 2016; Moore, Ayers, \& Drey, 2016).

One of the information sources that is becoming increasingly popular is the Internet in general and discussion forums in particular. Indeed the experiential nature of advice on forums can be valued above advice given by professionals (Doyle, 2013). Hall and Irvine (2009) found that mothers experienced many positives from interacting online, including the provision of emotional support. The community aspect of Internet forums can also be particularly useful in helping mothers in difficult situations. Kantrowitz-Gordon (2013) found that forums could provide a place for women to admit uncomfortable feelings such as feeling shame about depression. Whilst there can be conflicts of opinions and negative posters, the general sense from the literature is that parenting forums are positive sources of information and support for mothers that permits open discussion about feelings and experiences.

Most authors working on mothers' information seeking have focussed on the challenges of obtaining information, dealing with conflicting information and managing information sources, e.g. (Brown \& Rowan, 2015; Carolan, 2007). From these studies, we know a lot about the topics for which mothers need information; what is lacking is an account of the emotions felt by mothers at the time of asking for information. That is, what is the emotional context that mothers are experiencing when asking for information online?

\section{Young motherhood and information poverty}

Whilst motherhood is generally seen as a positive life experience, young motherhood is often treated as problematic due to the negative socio-economic effects of having a child at an early age. For example, young mothers are less likely to be in stable employment (Lombardi \& Coley, 2013), more likely to suffer post-partum depression (Kingston, Heaman, Fell, \& Chalmers, 2012), and more likely to suffer negative birth outcomes such as infant death, longer hospital stays, and low birth weight (Torvie, Callegari, Schiff, \& Debiec, 2015). Societally, there are arguments against young motherhood including increased medical costs (Maiden, Gunter, \& Martin, 2014), poorer life outcomes for their children (Nord, Moore, Morrison, Brown, \& Myers, 1992) and that younger mothers are more likely to receive fewer years of education than non-mothers (Kane, Morgan, Harris, \& Guilkey, 2013). Equally, there 
are arguments that these outcomes are poverty-based rather than an issue of early motherhood, e.g. (Wilson \& Huntington, 2006) and many young mothers may therefore be experiencing poverty and associated social difficulties. Many young mothers from deprived or challenging domestic backgrounds have found the experience of becoming a young mother a positive one that has led to many positive changes in other parts of their lives (Coleman \& Cater, 2006).

Whilst all mothers need strong social support and informational support, young mothers needs' may be different to older mothers (Cronin, 2003) and their general lack of life experience means they may need additional support that is not necessary for other mothers (Robb, McInery, \& Hollins Martin, 2013). Young motherhood can also be associated in some people's mind with low moral behaviour and young mothers often face stigma about their choice to become a young mother, which can impede their abilities to feel like an effective parent (Ellis-Sloan, 2014; SmithBattle, 2013). This can impact upon young mothers' willingness to ask for help or advice. Recent findings from the Growing Up in Scotland Survey, a longitudinal study of thousands of Scottish families, found that $42 \%$ of mothers under the age of 20 felt it was difficult to ask for help and advice unless you know the person well, and $30 \%$ felt that others would think you are a bad parent if you do ask for help (compared to only $9 \%$ of mothers over 25) (Bradshaw, Schofield, \& Maynard, 2014). Thus young mothers may prefer to seek information from family of friends, and report feeling judged and stigmatised by some professionals (Young Scot, 2015).

In her seminal work on Information Poverty, Chatman (1996) showed that unsupportive social settings could lead to people being unwilling to risk asking for information, in part due to the fear of what may happen when an information need is made known. A particular risk identified in her studies was the risk of judgment by others. This is particularly relevant to young motherhood where any perceived stigma felt by young mothers, particularly those becoming mothers for the first time and for whom motherhood is a new experience, may affect how they ask for information. In previous studies, including (Bronstein, 2014; Hasler et al., 2014) information poverty was identified as one motivating factor that leads people into online information seeking, not least because of the anonymity permitted by online interactions.

\section{Emotional analyses}

Information Science researchers have been interested in emotions, and recognised their importance, for decades but with little consensus on how to define emotions and what is actually being measured when we measure emotions (Lopatovska \& Arapakis, 2011; Savolainen, 2015). This is in spite of very early research, e.g. (Taylor, 1968), indicating that negative emotional states can be the motivating factor that leads to information seeking; a perspective recently revisited by Savolainen (2014) in a conceptual 
analysis of emotions motivating information seeking and who noted the predominance of studies involving negative emotions. As highlighted by Savolainen (Savolainen, 2014, 2015) the language of affect and emotion is often loose with related concepts such as emotion, mood, feeling, etc. being used almost interchangeably perhaps without the recognition by authors that they are different.

As Lopatovska and Arapakis (2011) explain there also many methodological choices about how to study emotion with techniques such as neuro-physiological techniques, observer reporting and selfreport being common. Historically, content analyses have also been a useful approach to studying emotion, e.g. as in Kuhlthau's seminal work on the Information Search Process (1993), and, increasingly, automated linguistic analyses, particularly sentiment analyses, are being used to understand the use of emotions within text (Pang \& Lee, 2008).

Analysing online posts allow us to analyse emotions being expressed at the same time as information is being requested and understand, from the poster's own words, what they perceive as the emotions they are experiencing. This subjective representation is closest to the concept of 'feeling' (Savolainen, 2014, 2015) and permits us to investigate what emotions are being experienced by online posters and how these emotions interact with other features of their online requests for information.

The lack of attention in the literature to the emotions experienced by young first-time mothers when seeking information, the increasing use of online forums by mothers and the stigma that can affect young motherhood gives rise to the following research questions for this paper:

Research question 1: What emotions do young first-time mothers express in online requests for information and support?

Research question 2: Does stigma often pertaining to young motherhood give rise to information poverty and is this expressed within online posts?

Research question 3: How do emotions and information poverty relate to the way young first-time mothers ask for information and support online?

\section{Methods}

We developed this study in three phases: data gathering, coding, and analysis. Data gathering consisted of identifying suitable forum data. We investigated several major forums and selected two that were large enough to supply sizable data, and whose posts focussed mostly on information seeking. Codes were first assigned to describe the dominant emotions expressed within the data. Existing typologies for emotions were ruled out, as explained below, and the study's emotion typology emerged gradually 
from the data. Codes for information poverty were then assigned based on descriptions from Chatman's original work and later uses of her theory applied to Internet data, e.g. (Bronstein, 2014; Hasler et al., 2014). One author created the coding schemes with borderline and difficult cases resolved with a second author. Cohen's Kappa and Light's Kappa were used to test the inter-coder reliability with a third author coding a randomly selected $10 \%$ of the data. The results of this test, presented below, did not lead to any changes in the coding scheme. The findings were then analysed with respect to our coding scheme. In line with generally agreed ethical standards for conducting online research, we only examined posts from major forums that do not require registration to view, from groups which are more likely to be considered 'public spaces' and which have more than 100 members (Eysenbach \& Till, 2001).

\section{Data}

The data for this study came from the NetMums' "Young Parents Support" forum ${ }^{1}$ and the BabyCentre forum. NetMums is the UK's biggest parenting website containing advice pages, new stories, chatrooms and forums. The "Young Parents Support" forum is specifically aimed at younger parents and is carefully moderated. NetMums was established in 2000, approximately $40 \%$ of its participants are from low-income backgrounds (Russell, 2012) and, with approximately 400 new topics being discussed each year, it is an active forum. As the "Young Parents Support" forum explicitly focusses on young parents, it concentrates on the needs of people who self-identify as being young parents, including expectant parents; overwhelmingly this is young mothers and pregnant women. The forum is publicly viewable without membership but posters must join in order to post. Membership is free and the forums allows anonymous posting so posters can protect their identity if posting on potentially controversial topics. NetMums has been the source of a wide range of studies (Russell, 2012). BabyCentre is similar to NetMums in that is a moderated, professional forum. However, it does not have a demarcated board for young parents and is less active than NetMums so provides less data. It has been used in other studies of young parents' information behaviour, e.g. (Jang, Dworkin, \& Connell, 2012; Papen, 2013).

We collected all posts to the NetMums' "Young Parents Support" forum from mid-August 2014 to midAugust 2015 to give one year's sample of posts. From this sample, we eliminated posts where the poster was clearly over 21 years old. We use 21 as an upper bound in our dataset as this is the age at which young people obtain full adult rights in the UK. We include posts from those posters who claim to be 21 , as they may have become mothers before the age of 21 .

\footnotetext{
${ }^{1}$ https://www.netmums.com/coffeehouse/advice-support-40/young-parents-support-500/ 
We also eliminated posts where the poster clearly states that she has more than one child; is neither a mother nor pregnant; is a relative of a young mother; has decided not to keep her baby; or is a father. These restrictions were to retain the focus of our study on young first time mothers. All posts were in English. Out of 405 posts, 240 posts from 204 individual young mothers or mothers-to-be met the criteria for inclusion. We also created a second dataset from the BabyCentre forum by taking a year's worth of postings covering a similar period and using similar inclusion rules as for our NetMums' dataset and obtaining 39 posts from 33 unique posters.

Of the combined data, 129 out of 237 posters clearly stated their age or gave sufficient detail to allow us to infer their age from their post. The most common age range was 19-20 (46.51\% of posters who provided an age or where we could infer an age) with many posters also in the age range 17-18 and with a mean age of 18.7 years. Those under 16 (the legal age of consent in the UK) may be more reluctant to provide their age when posting. There were no posters under the age of 14 .

\section{Analysis}

\subsubsection{Typology of emotions}

Our first research question was to examine the emotions expressed in online posts. As noted above, there is no single categorisation of emotions available, on the contrary there are many categorisations. Thamm (2006) in his study of emotional categorisation systems notes even a wide disagreement on how many emotions there are, with estimates ranging from 2 to over 80 .

Many systems, such as the influential categorisation of eight basic emotions (anger, fear, sadness, disgust, surprise, anticipation, trust, and joy) proposed by Plutchik (2001) are based on the view of emotions as being biological responses. When we tried coding with such schemes we found (a) the schemes based on small numbers of basic emotions lacked expressivity in describing the emotions we were uncovering in the posts and (b) particular dimensions, such as feelings of cognitive load, that were important themes within our data, were often completely lacking.

We were not trying in this research to detect which emotions, in the biological sense, the posters were experiencing, rather what feelings they were experiencing and describing, in the sense of their own understanding of their emotional state. In particular, we were interested in which feelings were described by the poster as motivating the need to ask for information. We then turned to approaches that use language to categorise emotions, e.g. that of Shaver et al. (1987). These have the major advantage that they provide classifications based on how people describe their emotions in everyday language. However, they have the major disadvantage of being large and unwieldly schemes. Shaver et 
al. for example provide a list of 213 emotions recognisable by most people. However, the major disadvantage of such comprehensive schemes is that they draw distinctions between very similar emotions such as sadness, misery and sorrow, whereas the posts that we were analysing were not using language with the same level of precision. Many of these schemes also lack detailed instructions on how to differentiate between emotions simply listing and grouping emotions. Interestingly, even in such large lists, many schemes also lacked codes for feelings such as confusion or stress that we were seeing in our posts.

Therefore, we created our own categories of emotions to reflect the emotional content of the posts using a purely inductive approach, starting with broad emotional labels and then iteratively refining the coding scheme until stabilised. We separately coded each of the 174 posts from 162 posters that contained significant emotional content with the dominant emotions expressed in the post. We were not trying to code every mention of emotion; particularly as some are indications of previous emotions states, (e.g. 'ive always been too proud to ask for help from anyone' is not coded as indicating pride). Rather we were coding the emotional states (if any were expressed) that seemed to lead to the poster writing the post, so phrases such as 'Im really worried', 'I'm suddenly getting very nervous', 'I am so so scared' were seen as meaningful in understanding what emotions were currently being experienced. We have allowed each post to be coded with more than one emotion, as there can be more than one emotion expressed (worry causing depression for example), but the emotions must be the mothers' emotions so we discount posts about a boyfriend's anger or a child's night terrors (a sleep disruption that seems similar to a nightmare), etc. The emotions were then grouped into three main emotional themes uncovered: interaction emotions, response emotions, and pre-occupation emotions, explained in more detail below.

One member of the project team created the coding scheme with borderline and difficult cases resolved with a second member of the team. We tested the inter-coder reliability by asking a member of the team who was not involved in the creation of the scheme to code $10 \%$ of the data and calculated the intercode reliability using Light's Kappa, which allows items to be coded under more than one category, resulting in a coefficient of 0.55 . The agreement between emotional themes was strong with most disagreement being around whether an emotion was displayed strongly enough in a post to warrant a code being attached rather than what emotion was being expressed.

The analytical approach described above was adopted to generate new insights into the ways in which young mothers utilise online forums. However, as with any methodology, there are limitations to our approach which should be noted. As this study focuses on the information and support needs of young 
first time mothers, only thread titles and first post were analysed and we did not analyse any responses. This study works with posts to online news groups and this is not a probabilistic sample of young first time mothers so we cannot make claims to generalisability regarding the distribution of emotions experienced by young first time mothers based on our study. We can also only work with what is expressed by posters, which may not be all the emotions they feel. For example, a post asking for new friends may not contain any explicit indicators of isolation even if the poster feels isolated.

\subsubsection{Information poverty coding}

Our second research question is to investigate whether the stigma and judgment that is often associated with young motherhood affects young mothers' information seeking and, precisely, does this group manifest signs of information poverty in their posts? Based on previous studies of online posts from marginalised groups such as (Bronstein, 2014; Hasler et al., 2014) we developed codes relating to Chatman's theory of Information poverty, specifically codes on secrecy, deception, risk and situational relevance which Chatman proposed were signals that someone may be in a situation of information poverty (Chatman, 1996).

The code Deception is applied when a main theme of the post describes a situation/emotions that are being hidden via active misrepresentation, e.g. pretending to be happy in a relationship. The poster may also be asking for advice about how to hide a situation, e.g. 'Does anybody know if you can get away with not telling the estate agents I am not returning to work'.

The code Relevance is applied when the poster states that she feels that only information coming from people in very similar situations will be useful and that they lack such support in their normal social environments. In these cases, there must have been an explicit request for shared experiences rather than simply being a request for socialisation or requests for help. That is, the poster indicates that she only wishes information from people who have been in similar situations using phrases such as 'I would appreciate people who haven't been in this situation not to comment.'

The code Risk is applied where the poster is afraid of the consequences of an action or afraid of the consequences of revealing her feelings or a situation, e.g. afraid of the risks of informing parents of a pregnancy. These posts explicitly mention risks and usually indicate of which consequences they are afraid, e.g. 'The only problem is my family...they will go absolutely mental and practically disown me [if she tells them she is moving]'. 
The code Secrecy is applied posts where the poster is hiding a situation or feeling but not actively using deception, e.g. 'do u think $i$ should tell his gf [about her ex-partner's sexual advances]?'.

\subsubsection{Interaction of emotions and information requests}

Our third research question is to investigate how the emotions experienced by young first-time mothers when asking for information interact with the way they ask for information. We answer this question by linguistic analyses of the posts. We do this in two ways.

Firstly we classify the posts into what Taylor (Taylor, 1968) called conscious and formalized information needs; posts that present a situation but no information need and posts that present a concrete information need. These distinguish between posts where the poster cannot yet formalize her situation into an information need (conscious needs) and cases where the post can identify what information she needs (formalized needs). Using the Linguistic Inquiry and Word Count (LIWC) software for text analysis ${ }^{2}$ we can compare how emotions appear within these two types of post to ascertain whether the emotions being expressed relate to being able to express a clear information need.

Secondly, we look at the co-occurrence between emotions expressed in posts and information poverty codes to determine whether there is a relationship between expressing information poverty signals within a post and expressing specific types of emotions.

\section{Findings}

\section{Emotions expressed in online posts}

Our first research question was what emotions do young first-time mothers express in online requests for information and support? Table 1 presents the main emotional categories identified, the number of posts coded with each emotion and the percentage of all posts that contained that emotion. There are three main emotional themes: interaction emotions, response emotions, and pre-occupation emotions.

\begin{tabular}{|l|l|l|l|}
\hline Emotional theme & Emotion & Number of posts & $\%$ age \\
\hline interaction emotions & isolation & 47 & $16.85 \%$ \\
\hline & judgement & 33 & $11.83 \%$ \\
\hline & pressurised & 9 & $3.23 \%$ \\
\hline pre-occupation emotions & worry & 45 & $16.13 \%$ \\
\hline
\end{tabular}

\footnotetext{
${ }^{2}$ https://liwc.wpengine.com/
} 


\begin{tabular}{|l|l|l|l|} 
& overwhelmed & 40 & $14.34 \%$ \\
\hline & self-doubt & 27 & $9.68 \%$ \\
\hline & confusion & 20 & $7.17 \%$ \\
\hline & fear & 17 & $6.09 \%$ \\
\hline response emotions & stress & 12 & $4.30 \%$ \\
\hline & anger, frustration, venting & 26 & $9.32 \%$ \\
\hline & depression & 14 & $5.02 \%$ \\
\hline & happiness, love, excitement & 8 & $2.87 \%$ \\
\hline
\end{tabular}

Table 1: Emotions expressed in posts

\subsubsection{Interaction emotions}

Emotions within the interaction emotions category relate to interactions with other people or a lack of interaction. What is characteristic of these posts is that the emotion is directed towards a sense of poor interaction with another person: either a lack of interaction (isolation), interaction in the form of coercion (feeling pressurised) or interaction leading to a feeling of being judged (judgement). 75 unique posts out of the total $279(26.9 \%)$ contained an interaction emotion ${ }^{3}$.

Almost $17 \%$ of the total posts strongly expressed some sense of Isolation, either the fact of being isolated, feeling isolated or worried about being isolated in a future situation such as going to college or moving city. Posts in this category contain explicit expressions of loneliness or isolation, simply making general requests to meet other mothers does not indicate isolation. This is a very common emotion in our dataset, often reflecting the change in social situations experienced by young first time mothers whose friends are typically not mothers, e.g. 'I'm 29 weeks pregnant with my first baby (a boy) and I'm starting to feel really lonely and isolated!' and 'I guess I'm just looking for people who understand me who may have gone through something similar. Just feeling really lonely in this situation.'

Judgement was expressed, in the form of feelings or experiences of being judged negatively, in about $12 \%$ of posts. We did not count official judgements such as decisions about benefits or cases where the poster asks not to be judged for her situation. Judgments described may come from family, partners or strangers in the street and the judgement may be on the poster's child in the case of disability or difficult

\footnotetext{
${ }^{3}$ Some posts contain more than one interaction emotion so the number of unique posts does not equal the total number of interaction posts in Table 1.
}

12 
behaviour. Frequently, the judgement is self-judgement as mothers express their concerns about whether they are doing a good job as a mother. The judgement may be real, perceived or potential. Examples include: 'I have no family to talk to as my parents hate me for getting pregnant'.

A minority but important theme was feeling Pressurised, appearing in about 3\% of all posts. These describe situations where someone tries to persuade or coerce the poster into acting in a particular way or to agree to something. This is nearly always her partner or her family and covers situations of where to live, whether or not to breastfeed, and whether or not to terminate a pregnancy. This category also covers situations where implicit pressure is applied to get the poster to behave in a particular way, e.g. 'but surely i shouldn't feel under pressure to breastfeed just because he [partner] is listening to the media'.

\subsubsection{Pre-occupation emotions}

These emotions are all concerned with states of mental absorption. Challenging situations or difficult information needs can result in people not knowing their own mind and needing to think through a problem. Similarly, posters are often in a dilemma because they lack information or because they are waiting for either information or for someone else to make a decision. These states of uncertainty are common amongst posters and it is possible to separate out different kinds of states of uncertainty within these posts. 141 unique posts out of the total 279 (50.5\%) contained a pre-occupation emotion.

Almost 7\% of all posts expressed the state of bewilderment in the poster's mind about a situation or about another person or about what is expected from the poster in their current situation, reflecting a state of Confusion. Confusion does not apply to every state of uncertain knowledge but refers to an explicitly stated decision that has to be made by the poster, e.g. 'I am in two minds about contacting them [boyfriends' parents] as I dont know how they'll respond or what they'll think of me.' ' and 'Iv really got no idea what to do at all...do I bite the bullet and do what $i$ want?'

Almost $6 \%$ of all posts expressed Fear, an unpleasant emotion caused by the threat of harm or psychological discomfort or some kind of loss. These posts are categorised under worrying emotions rather than response emotions as nearly all contain some kind of conditional nature representing fear of some possible future rather than fear in response to an actual situation or person, e.g. fear about being isolated if they go to college, fear about the consequences if they visit the doctor, etc. A good example is 'My social workers have reassured me that they won't be taking the baby away from me or anything drastic, they just want me to have the full support. Is there any other teen moms on here?? This is 
obviously my first child and I am so scared!!' where the subjective fear is strong even though the poster knows the threat is objectively weak.

A common theme, appearing in over $14 \%$ of our posts, was feeling Overwhelmed or feeling unable to cope with a situation. There may be one problem or many but what is characteristic, unlike in the categories of stress or worry, is that the posters have the feeling that they are failing to cope or in danger of being out of control. Examples in this category include 'I feel over whelmed like I can't cope with everything and i don't know what to do or who to talk to...'.

Self-doubt appears in 10\% of posts, describing situations where the poster is asking others to comment on their judgement about a situation (e.g. 'am I right to feel this way') or looking for reassurance that they are doing a good job as a mother. In the former case, the poster feels uncertain about a situation, such her child's health, partner's behaviour or interactions with professionals, and is testing her intuition about whether she is right to be concerned. In the latter case the poster is asking, or hinting, that she wishes people to validate her as a decent person and good mother using phrases such as "please no one think bad of me I am a good person'. Validation is an important aspect of these posts and occasionally this validation is about the future, e.g. 'is it possible for a young person to be a good mother?'.

Stress appears in $4 \%$ of all our posts. These express a state of mental or emotional strain resulting from specific named circumstances. These are focussed circumstances, such as lack of money or a poor housing situation, which result in focussed stress rather than just generalised anxiety over being a mother. This code also includes situations where a mother asks about consequences of stress or how to deal with stress, examples including 'Does anyone have any advice regarding stress and how I can calm myself down so I don't hurt baby', and 'He wint let me put him down, its causing so much stress in and out of me and my partners relationship, don't know what to do any ideas'.

Worry is the single most common emotion expressed in our sample with $16 \%$ of posts strongly expressing the state of being anxious and troubled over actual or potential problems, sometimes these are acute, sometimes chronic. This code is separate to the stress code in that there is no feeling of cognitive or emotional load in these posts, it is different to the overwhelmed code in that there is no expressed sense of being unable to cope. Examples include: 'im 27 weeks pregnant and extremely worried about everything.' and 'I'm pretty worried, \& I can't call docs till 5 PM tomorrow because of work, anybody have any ideas'. 


\subsubsection{Response emotions}

This group of emotions are ones where the dominant emotion is a reaction to someone else or a situation: anger or frustration being the main negative emotions and happiness or love the main positive ones. All the posts are directed towards the cause of these emotions. 45 unique posts out of the total $279(16.1 \%)$ contained a response emotion indicating this was not a widely expressed group of emotions amongst our posters.

Anger, frustration, venting posts expressed anger directly or expressed a response to feeling attacked or treated unfairly. This feeling of being treated unfairly can lead to feeling of frustration or posters may express the feeling of being frustrated as a result of being unable to change or achieve something such an improved relationship, obtaining a job, applying for benefits etc. The reason for being frustrated or angry has to be specific; feeling a general sense of being unable to cope is coded under the code overwhelmed. Many posters expressed the need to give expression to their frustration and often reported a need to vent (a common term used by posters) as the reason for posting. This was a frequent reaction with almost $9 \%$ of posts in this category. Examples include: 'I don't know what I expect from posting this, but I just felt like I had to let my emotions out', and 'Sorry for the very long message just had to let it all out'.

Many posters are unhappy but 5\% of all posts explicitly state they are Depressed and express feelings of rejection and low mood, 'As it [housing situation] is stressing us all out and making us depressed' and 'Very lonely I'm recently single, baby due in less than 2 months and I have 0 friends. It's really getting me down:( '. Posts coded as depression include a named cause of the poster's depression rather than depression being simply reported as a state.

When there are no problems there is little impetus to interact with strangers online and it is therefore not surprising that positive stages of mind such as Happiness, love, excitement contain the smallest number of posts, $3 \%$ of the total of 279 posts. Posts in this category express happiness in the state of new motherhood, excitement at forthcoming events, including giving birth, or discuss feelings of love for their child. Although most posters are happy with their child, these posts explicitly mention this state. Examples include: 'My due date is ... Super exciting ... Just looking for people I can talk to and learn from', and 'Its particularly hard trying to complete your dissertation when all you want to do is stare at your beautiful baby'.

We allowed posts to be coded with more than one emotion if the posts contained more than one dominant emotion. In practice, the overwhelming number of posts only contained one dominant 
emotion. The most common emotions expressed in the posts were worry, feeling overwhelmed and isolated: common emotions to many new mothers but perhaps heightened amongst this particularly young group of new mothers. That these emotions are reflected in nearly half of all posts in the sample suggests that online forums provide a valued space to "vent" these feelings. The posts are a mixture of cases where young people chose to seek support online rather than within close family and friend networks or cases where they feel that they cannot ask for information from their social groups.

\section{Stigma and information poverty}

Our second research question was to investigate whether the stigma and judgment that is often associated with young motherhood affects young mothers' information behaviour and, specifically, does this group manifest signs of information poverty in their online information seeking?

In 57 out of the 279 posts in our sample an information poverty code was applied and these posts came from 52 posters. That is, $20 \%$ of posts and $22 \%$ of posters demonstrated some form of information poverty in their posts with relevance and risk being most prevalent. An inter-coder reliability test showed a Cohen's Kappa coefficient of 0.62 , good agreement strength on when and which codes to apply with most disagreement coming from when to apply the code rather than which code to apply.

In our data, Deception was used in only 6 posts. Sometimes this was to provide advantage, for example to overcome housing restrictions. More often, deception to buy time until the poster has worked out how to move forward in a situation, for instance pretending that a relationship is successful until the poster has decided whether or not to continue with the relationship. Sometimes the main goal of the post was to elicit techniques to continue with the deception. Examples of these posts included what excuses will justify not avoid drinking alcohol at family gatherings when concealing a pregnancy.

Relevance was expressed in 30 posts, almost $10 \%$ of all posts. Relevance was focussed in three ways: relevance based having a similar experience ('looking for people who understand me who may have gone through something similar'), relevance based on being a young mum ('Would love to chat with any other younger mums who probably face the same struggles and share the same experiences as I $d o^{\prime}$ ) or having a child with similar characteristics or experiences ('anyone else's baby has done this').

Risk was expressed in 16 posts, almost $6 \%$ of the total. Risks expressed include risks of informing parents of a pregnancy, the risks of informing professional services about a change in personal circumstances, afraid of returning to school, dealing with a relationship, etc. These posts mention risks and usually indicate of which consequences they are afraid. Examples include: 'I am in two minds about 
contacting them [boyfriends' parents] as I dont know how they'll respond or what they'll think of me.', and 'But what are the implications of telling $h v$ [health visitor]?'.

Secrecy was not used often, only appearing in 5 posts. What was hidden was usually emotional, including unhappiness in a relationship, unhappiness in a housing situation, or confusion over a situation, for example not wishing to receive advice from a partner 'I feel like i can't tell him to just stop [giving advice] because he thinks he is trying to help me?'.

\section{Emotions interacting with posting styles}

Our third research question was to investigate how young first-time mothers ask for information and support online, differentiating between Taylor's (1968) conscious and formalized types of information need. Using the Linguistic Inquiry and Word Count dictionary-based software for text analysis we analyse these two types of posts linguistically. LIWC provides several categories relating to emotion, specifically the categories affect (representing general emotional words), positive emotions, negative emotions, anxiety, anger and sadness related words. The results are summarised in Table 2, indicating what percentage of words, on average, from each belong to each LIWC category, with statistical significance measured using a Mann Whitney test. We also use the LIWC category called Analytic which gives a score, out of 100 , to text to reflect the degree of analytical thinking expressed in the posts; high numbers reflect text that is more formal and logical, low numbers reflect more informal, personal and narrative thinking.

We see that conscious posts contain significantly more affect words and are significantly more negative in emotional tone with a higher use of negative emotions, a significantly higher use of anxiety-related, anger-related and sadness-related words. Conscious posts are also significantly less analytic than formalized posts.

\begin{tabular}{|l|l|l|l|}
\hline linguistic variable (\% of total words) & conscious & formalized & significance level \\
\hline affect words & $5.0 \%$ & $4.4 \%$ & $\mathrm{p}=0.049$ \\
\hline positive emotions & $2.4 \%$ & $2.6 \%$ & $\mathrm{p}=0.539$ \\
\hline negative emotions & $2.6 \%$ & $1.7 \%$ & $\mathrm{p}<0.001$ \\
\hline anxiety-related words & $0.75 \%$ & $0.54 \%$ & $\mathrm{p}=0.001$ \\
\hline anger-related words & $0.41 \%$ & $0.28 \%$ & $\mathrm{p}<0.001$ \\
\hline sadness-related words & $0.66 \%$ & $0.39 \%$ & $\mathrm{p}=0.001$ \\
\hline Analytic & 23.65 & 38.30 & $\mathrm{p}<0.001$ \\
\hline
\end{tabular}


Table 2: Linguistic analyses of formalized and conscious posts

We performed a series of Chi-Square tests of independence to examine the interactions between the types of posts (conscious/formalized) and the various classes of emotions and signals of information poverty. Our results are summarised in Table 3 and show that all types of emotions (interaction, preoccupation, response) manifested significantly more often in conscious than formalized posts. Cramer's Phi gives an indication of the effect size of the relationship with 0.1 indicating a small effect size, and 0.3 a medium effect size. We can see that the strongest relationship was between preoccupation emotions and conscious posts indicating that these 'worrying' emotions were mostly likely to appear in posts where the poster could not formulate a concrete information need.

\begin{tabular}{|l|l|l|l|l|l|}
\hline & conscious & formalized & $\begin{array}{l}\chi^{2}(2, \\
\mathrm{N}= \\
\left.265^{4}\right)\end{array}$ & $\begin{array}{l}\text { significance } \\
\text { level }\end{array}$ & $\begin{array}{l}\text { Cramer's } \\
\text { Phi }\end{array}$ \\
\hline $\begin{array}{l}\text { Interaction emotions } \\
(\% \text { of posts that contain an } \\
\text { interaction emotion })\end{array}$ & $42.11 \%$ & $15.88 \%$ & 22.18 & $\mathrm{p}<0.001$ & 0.289 \\
\hline $\begin{array}{l}\text { Preoccupation emotions } \\
(\% \text { of posts that contain a } \\
\text { preoccupation emotion })\end{array}$ & $71.56 \%$ & $34.71 \%$ & 33.20 & $\mathrm{p}<0.001$ & 0.354 \\
\hline $\begin{array}{l}\text { Response emotions } \\
(\% \text { of posts that contain a } \\
\text { response emotion })\end{array}$ & $13.68 \%$ & $5.88 \%$ & 3.248 & $\mathrm{p}=0.031$ & 0.133 \\
\hline Information Poverty codes & $32.63 \%$ & $11.76 \%$ & 17.08 & $\mathrm{p}<0.001$ & 0.254 \\
\hline
\end{tabular}

Table 3: Chi-square tests on the relationship between emotions, information poverty and type of post

A Chi-Square test of independence examined the relation between the type of post (formalized/conscious) and presence of information poverty codes. This relationship was significant with a reasonable effect size, indicating that information poverty codes were significantly more likely to be expressed in conscious than formalized posts.

\footnotetext{
${ }^{4}$ In these analyses we used the 265 posts which either contained a conscious or fomalized need 
A final Chi-Square test examined whether the presence of information poverty codes are independent of the type of emotions presented, Table 4. The results showed both interaction and preoccupation emotions are more likely to be expressed when information poverty codes are present. The strongest relationship was between the presence of information poverty and interaction emotions (isolation, pressurised, judgment) indicating that the posters who are most likely to be demonstrating signs of information poverty are also those ones most likely to be experiencing poor relationships with people in their immediate social circles.

\begin{tabular}{|l|l|l|l|l|l|}
\hline & $\begin{array}{l}\text { Information } \\
\text { Poverty present }\end{array}$ & $\begin{array}{l}\text { Information } \\
\text { Poverty absent }\end{array}$ & $\begin{array}{l}\chi^{2}(2, \mathrm{~N} \\
=279)\end{array}$ & $\begin{array}{l}\text { Significance } \\
\text { level }\end{array}$ & $\begin{array}{l}\text { Cramer's } \\
\text { Phi }\end{array}$ \\
\hline $\begin{array}{l}\text { Interaction emotions } \\
\text { (\% of posts that contain } \\
\text { an interaction emotion) }\end{array}$ & $55.36 \%$ & $18.83 \%$ & 30.91 & $\mathrm{p}<0.001$ & 0.333 \\
\hline $\begin{array}{l}\text { Preoccupation } \\
\text { emotions } \\
(\% \text { of posts that contain } \\
\text { a preoccupation } \\
\text { emotion })\end{array}$ & $62.50 \%$ & $44.84 \%$ & 5.59 & $\mathrm{p}=0.018$ & 0.142 \\
\hline $\begin{array}{l}\text { Response emotions } \\
(\% \text { of posts that contain } \\
\text { a response emotion })\end{array}$ & $12.50 \%$ & $8.52 \%$ & 0.839 & $\mathrm{p}=0.360$ & 0.055 \\
\hline
\end{tabular}

Table 4: Chi-square tests on the relationship between emotions and information poverty

\section{Discussion}

In this paper, we examined the emotions expressed by young first time mothers when asking for information and support. This is a group of people who are undergoing a major life transition and who may be in particularly vulnerable emotional situations, wanting to be good parents but unsure of their new roles. The data we used were online posts made by young women who may feel they lack good sources of information in their daily lives and, in some cases, were using online forums to avoid asking particular individuals, such as family or professional services, about areas of concern.

Our dataset was a year's worth of postings to two major UK discussion groups for young mothers. Almost two-thirds of the posts had a strong emotional content reflecting the posters emotional state when posting the request for information or support. We found that these emotions could be categorised 
into three main themes. The most common, expressed in over half the posts, were preoccupation emotions reflecting states of cognitive load and uncertainty (confusion, doubt, stress, etc.). It is not surprising that new mothers need information and support but what was clear in our data set was the considerable negative emotions associated with these needs. That negative emotions leads to information seeking fits with the arguments of authors such as (Savolainen, 2015). The emotions that were most often expressed were what we referred to as pre-occupation emotions (worry, self-doubt, confusion, etc.). That these were common emotions fits with finding from authors such as Kuhlthau who noted the uncomfortable feelings caused by cognitive uncertainty (Kuhlthau, 1993). Notably, existing emotional schemes did not adequately reflect these emotions expressed by young women in their posts, creating a need to devise a new scheme that could better capture their feelings of confusion and anxiety.

These posts were not made from a position of confidence in their new lives. While most posters expressed happiness in their situation as new or expectant mothers, they were also overwhelmed, worried and felt considerable self-doubt about how to provide the best possible environment for their child. These emotions were strongly associated with Taylor's (1968) concept of conscious information needs, that is in posts where the poster cannot yet express a concrete information need but can only describe to various degrees a problematic situation that is giving rise to feelings of concern. This type of post was also most strongly associated with expressions of information poverty, indicating that the poster also lacked people who could help work through the situation. Conscious posts - one where the poster feels strong negative emotions but cannot yet work through to expressing what information or support would help - is a particularly interesting area in thinking about what support might be appropriate to provide in terms of professional help and how this might be provided. These young women know that they need information and are actively searching for it, but would appear to require support in identifying and resolving often complex problems.

Almost $10 \%$ of posts were explicitly seeking information from other mothers who had experienced similar needs. Seeking information from those in similar situations accords with the theory of Davison et al. (2000) in their studies of social support groups, and their claim that affiliative behaviours - looking for people who are similar - often increases during times of anxiety as we look for people who are similar for understanding and that the shared experiences of others can be more important than professional information structures.

The language used in online posts can serve as powerful indicators of underlying states of mind around critical situations (Owen et al 2005), and linguistic indicators of emotions (the words young women are 
using to describe their emotions and possible information poverty) potentially provide a means for identifying posters who would benefit from additional support. Huh et al. (2013) for example that linguistic analyses can be useful for determining automatically which posts require attending from a moderator and which did not. Our findings could help determine which posters are at the early stages of problem recognition (conscious needs) and which are later in the stage of being able to express needs.

Appropriate responses to requests for help are important. For example, Wang et al. (2012) looked at linguistic analysis of discussions health groups and showed that those who receive emotional support are more likely to stay within the group and those who received informational support more likely to leave (having possibly their questions answered). Thus, by recognising and responding to posters displaying a high level of emotional need forums may be able to better retain these young women, and help to reduce the isolation expressed by many of the mothers in our sample.

Indeed, isolation was the most commonly expressed of the interaction emotions (a category which included feeling judged, pressurised or isolated) we analysed, with almost a fifth of young women articulating feelings of this kind. The presence of these emotions, that indicate poor social environments, were strongly associated with posting situational rather than informational posts and most strongly associated with information poverty. Studies of mothers' preferred information sources, e.g. (Loudon et al., 2016), show that the preferred source for answering information needs are close family, friends and other mothers. Importantly, the young women in our study who appear to lack such a supportive networks are also the individuals whose posts indicate the most complex levels of need and greatest emotional distress. For these mothers, online forums may be a crucial source of information and support.

Further, our analysis also suggests that a significant subset of posters demonstrated some signs of information poverty. Sometimes this was their new situation leading to having to employ deception or secrecy, sometimes because motherhood introduces new risks (particularly the risk of social services removing their child) but, most often, it was the belief that only other young mothers could help and only information from this group was valuable. As was shown above, those posts that were more emotional in content were also those ones that were most likely to demonstrate information poverty. Although we cannot formally analyse levels of information poverty using our data (which does not allow for interaction with the posters), from contextually reading the posts it does appear that information poverty is spectrum-like with some posters feeling afraid of any potential risk to their motherhood and, at the other end of the spectrum, posters feeling free to ask for information. 


\section{Conclusions}

Internet forums offer the possibility to discuss difficult aspects of life in supportive environments. This study has looked at the particular context of young first-time mothers and expectant mothers, revealing a rich range of emotions expressed in online posts to improve our understanding of the context in which young mothers ask for help. These women are happy to be mothers and aiming at being successful mothers, whilst facing significant challenges in housing, finance, changing relationships, and, often, the negative attitudes of others. Through examining the posts, we can see how they think through their own personal situation and better distinguish between the various ways that they are asking for support. Beyond advancing our understanding of the role of Internet forums in the everyday lives of young mothers, this study shows how different types of post differ in emotional context and how these emotional contexts interact with the poster's own understanding of the problems described in their requests for help.

\section{Acknowledgments}

This research was funded by ESRC grant ES/L012634/1, Understanding the Information Needs of Young First Time Mothers from Areas of Multiple Deprivation.

\section{References}

Bondas, T., \& Eriksson, K. (2001). Women's lived experiences of pregnancy: A tapestry of joy and suffering. Qualitative Health Research, 11(6), 824-840.

Bradshaw, P., Schofield, L., \& Maynard, L. (2014). The experiences of mothers aged under 20: Analysis of data from the Growing Up in Scotland study. growingupinscotland.org.uk/wpcontent/uploads/2013/04/guideforLAs.pdf.

Bronstein, J. (2014). Is this OCD?: Exploring conditions of information poverty in online support groups dealing with obsessive compulsive disorder. Information Research, 19(4), http://InformationR.net/ir/19-14/isic/isic16.html

Brown, A., \& Rowan, H. (2015). Maternal and infant factors associated with reasons for introducing solid foods. Maternal \& child nutrition.

Carolan, M. (2007). Health literacy and the information needs and dilemmas of first-time mothers over 35 years. Journal of Clinical Nursing, 16(6), 1162-1172.

Chatman, E. A. (1996). The impoverished life-world of outsiders. JASIS, 47(3), 193-206.

Coleman, L., \& Cater, S. (2006). 'Planned' Teenage Pregnancy: Perspectives of Young Women from Disadvantaged Backgrounds in England. Journal of Youth Studies, 9(5), 593-614. 
Cronin, C. (2003). First-time mothers-identifying their needs, perceptions and experiences. Journal of Clinical Nursing, 12(2), 260-267.

Darvill, R., Skirton, H., \& Farrand, P. (2010). Psychological factors that impact on women's experiences of first-time motherhood: a qualitative study of the transition. Midwifery, 26(3), 357-366.

Davison, K. P., Pennebaker, J. W., \& Dickerson, S. S. (2000). Who talks? The social psychology of illness support groups. American Psychologist, 55(2), 205-217.

Doyle, E. (2013). Seeking advice about children's health in an online parenting forum. Medical Sociology Online, 7(3), 17-28.

Drentea, P., \& Moren-Cross, J. L. (2005). Social capital and social support on the web: the case of an internet mother site. Sociology of health \& illness, 27(7), 920-943.

Ellis-Sloan, K. (2014). Teenage mothers, stigma and their'presentations of self'. Sociological Research Online, 19(1), 9.

Eysenbach, G., \& Till, J. E. (2001). Ethical issues in qualitative research on internet communities. BMJ : British Medical Journal, 323(7321), 1103-1105.

Hall, W., \& Irvine, V. (2009). E-communication among mothers of infants and toddlers in a communitybased cohort: A content analysis. Journal of advanced nursing, 65(1), 175-183.

Hasler, L., Ruthven, I., \& Buchanan, S. (2014). Using internet groups in situations of information poverty: Topics and information needs. Journal of the Association for Information Science and Technology, 65(1), 25-36.

Huh, J., Yetisgen-Yildiz, M., \& Pratt, W. (2013). Text classification for assisting moderators in online health communities. Journal of biomedical informatics, 46(6), 998-1005.

Jang, J., Dworkin, J., \& Connell, J. (2012). Babycenter. com: New parent behavior in an online community. Paper presented at the The Forum for Family and Consumer Issues.

Kane, J. B., Morgan, S. P., Harris, K. M., \& Guilkey, D. K. (2013). The Educational Consequences of Teen Childbearing. Demography, 50(6), 2129-2150. doi: 10.1007/s13524-013-0238-9

Kantrowitz-Gordon, I. (2013). Internet Confessions of Postpartum Depression. Issues in Mental Health Nursing, 34(12), 874-882. doi: 10.3109/01612840.2013.806618

Kingston, D., Heaman, M., Fell, D., \& Chalmers, B. (2012). Comparison of adolescent, young adult, and adult women's maternity experiences and practices. Pediatrics, 129(5), e1228-e1237.

Kuhlthau, C. C. (1993). Seeking meaning. Norwood, NJ: Ablex.

Lombardi, C. M., \& Coley, R. L. (2013). Low-Income Mothers' Employment Experiences: Prospective Links with Young Children's Development. Family Relations, 62(3), 514-528. 
Lopatovska, I., \& Arapakis, I. (2011). Theories, methods and current research on emotions in library and information science, information retrieval and human-computer interaction. Inf. Process. Manage., 47(4), 575-592. doi: 10.1016/j.ipm.2010.09.001

Loudon, K., Buchanan, S., \& Ruthven, I. (2016). The everyday life information seeking behaviours of first-time mothers. Journal of Documentation, 72(1), 24-46. doi: doi:10.1108/JD-06-2014-0080

Maiden, K., Gunter, W. D., \& Martin, S. S. (2014). Teen mothers, unintended pregnancies, and costs across Delaware. Del Med J, 86(4), 109-116.

Moore, D., Ayers, S., \& Drey, N. (2016). A thematic analysis of stigma and disclosure for perinatal depression on an online forum. JMIR mental health, 3(2), e18.

Nord, C. W., Moore, K. A., Morrison, D. R., Brown, B., \& Myers, D. E. (1992). Consequences of TeenAge Parenting. Journal of School Health, 62(7), 310-318. doi: 10.1111/j.1746-1561.1992.tb01249.x

Nyström, K., \& Öhrling, K. (2004). Parenthood experiences during the child's first year: literature review. Journal of advanced nursing, 46(3), 319-330.

O'Mahen, H. A., Woodford, J., McGinley, J., Warren, F. C., Richards, D. A., Lynch, T. R., \& Taylor, R. S. (2013). Internet-based behavioral activation-Treatment for postnatal depression (Netmums): A randomized controlled trial. Journal of affective disorders, 150(3), 814-822.

Pang, B., \& Lee, L. (2008). Opinion mining and sentiment analysis. Foundations and Trends $^{\circledR}$ in Information Retrieval, 2(1-2), 1-135.

Papen, U. (2013). Conceptualising information literacy as social practice: a study of pregnant women's information practices. Information Research, 18(2).

Plutchik, R. (2001). The Nature of Emotions Human emotions have deep evolutionary roots, a fact that may explain their complexity and provide tools for clinical practice. American Scientist, 89(4), 344-350. Robb, Y., McInery, D., \& Hollins Martin, C. J. (2013). Exploration of the experiences of young mothers seeking and accessing health services. Journal of Reproductive and Infant Psychology, 31(4), 399-412. Russell, S. (2012). Social networking research opportunities: the example of 'Netmums'. Journal of Research in Nursing, 17(2), 195-206.

Savolainen, R. (2014). Emotions as motivators for information seeking: A conceptual analysis. Library \& Information Science Research, 36(1), 59-65.

Savolainen, R. (2015). Approaching the affective factors of information seeking: the viewpoint of the information search process model. Information Research: An International Electronic Journal, 20(1), n1.

Shaver, P., Schwartz, J., Kirson, D., \& O'connor, C. (1987). Emotion knowledge: further exploration of a prototype approach. Journal of Personality and Social Psychology, 52(6), 1061. 
SmithBattle, L. I. (2013). Reducing the stigmatization of teen mothers. MCN: The American Journal of Maternal/Child Nursing, 38(4), 235-241.

Taylor, R. S. (1968). Question-negotiation and information seeking in libraries. College \& research libraries, 29(3), 178-194.

Thamm, R. A. (2006). The Classification of Emotions. In J. E. Stets \& J. H. Turner (Eds.), Handbook of the Sociology of Emotions (pp. 11-37). Boston, MA: Springer US.

Torvie, A. J., Callegari, L. S., Schiff, M. A., \& Debiec, K. E. (2015). Labor and delivery outcomes among young adolescents. American journal of obstetrics and gynecology, 213(1), 95. e91-95. e98.

Wang, Y.-C., Kraut, R., \& Levine, J. M. (2012). To stay or leave?: the relationship of emotional and informational support to commitment in online health support groups. Paper presented at the Proceedings of the ACM 2012 conference on Computer Supported Cooperative Work.

Wilson, H., \& Huntington, A. (2006). Deviant (m) others: The construction of teenage motherhood in contemporary discourse. Journal of social policy, 35(1), 59-76.

Young Scot (2015), Co-Designing The Teenage Pregnancy \& Young Parent Strategy, Edinburgh: Scottish Government. Available at: http://www.youngscot.net/wp-content/uploads/2014/11/TeenagePregnancy-and-Young-Parent-Strategy.pdf 